\title{
VARIABILIDAD EN LA PRODUCCIÓN \\ DE PALAS Y/O AZADAS LÍTICAS DE \\ LA PUNA ARGENTINA
}

\author{
Susana Pérez ${ }^{1}$
}

\section{* Introducción}

Resumen

Se analiza desde una perspectiva técnico-morfológica el conjunto de palas y/o azadas líticas provenientes de dos regiones distintas de la Puna argentina: sitio Casa Chávez Montículo (depto. Antofagasta de la Sierra, Catamarca, Puna Meridional) y Doncellas (depto. de Cochinoca, Jujuy, Puna Septentrional). Los resultados reflejan una gran variabilidad en la técnica de manufactura, en la morfología general de los artefactos y en la materia prima utilizada en ambos conjuntos.

Palabras claves: Puna argentina - palas y/o azadas - tecnología - líticos.

\begin{abstract}
The variability of the assemblages of lithic shovels and/or hoes from two regions of the argentinian Pune: site Casa Chávez Montículo (department of Antofagasta de la Sierra, Catamarca, Southern Pune), and Doncellas (department of Cochinoca, Jujuy, Northern Pune), is analysed from a technic-morphological perspective. The results reflect a great variability in the manufacture technique, general morphology of the artefacts and raw material used in both assemblages.

Key words: argentinian Pune - shovels and/or hoes - technology - lithics.
\end{abstract}

Recibido: noviembre 2008. Aceptado: febrero 2010.

1 Instituto Nacional de Antropología y Pensamiento Latinoamericano y Pontificia Universidad Católica Argentina, 3 de febrero 1370/78 (1426) Buenos Aires, ARGENTINA. Email: superez@speedy.com.ar
En este trabajo nos centramos en la producción y variabilidad de palas y/o azadas líticas de la Puna del Noroeste Argentino, desde la perspectiva de la organización tecnológica (Nelson 1991), con el fin de analizar las estrategias involucradas durante el proceso de transición de las sociedades agropastoriles tempranas, ocurrido hacia 1000 $\mathrm{AP}$, a aquellas con economías productoras.

Nuestro objetivo es establecer esa relación a través del cambio tecnológico que acompañó a la complejización de las sociedades que poblaron el Noroeste Argentino (en adelante NOA), desde un punto de vista tecnofuncional, así como las actividades llevadas a cabo. Para ello, abordaremos la discusión a partir del estudio de un instrumento muy particular que cumplió un papel vital en las sociedades agropastoriles, las palas y/o azadas líticas. De este modo, dentro de nuestros objetivos están: el estudio de la tecnología involucrada en la manufactura de los instrumentos, los efectos del enmangamiento, la identificación del área usada, la caracterización de los materiales, la determinación de la forma de utilización y de las actividades desarrolladas.

La variabilidad de los instrumentos constituye un indicador de cambio importante para analizar la organización tecnológica, la variabilidad funcional de los mismos, y la clave para interpretar las actividades llevadas a cabo por los diferentes grupos sociales.

Desde la controversia surgida en la década de 1960 entre Bordes y Binford acerca del significado de la variabilidad instrumental observada durante el Musteriense en el sur de Francia (p.e., Bordes 1961; Binford y Binford 1966; 
Bordes y Sonneville-Bordes 1970; Binford 1973), los patrones de variabilidad en los conjuntos artefactuales líticos han sido atribuidos a causas tecnológicas, estilísticas, funcionales o procesos aleatorios, aunque solo las tres primeras tendrían significancia cultural (Yerkes y Kardulias 1993: 91). Estos mismos autores agregan, que la variabilidad estilística se refiere a las ideas impuestas culturalmente acerca de cómo los instrumentos de piedra pueden ser adecuados, mientras que la variabilidad funcional es el resultado del uso real de los artefactos, y la variabilidad tecnológica, el resultado de la aplicación de diferentes técnicas de manufactura durante su producción. En general, se considera que estos tres tipos de variabilidad son el resultado de procesos discretos, aunque algunos investigadores creen que la expresión estilística y el uso funcional se logran a través de la actividad tecnológica (Phagan 1976, cit. en Yerkes y Kardulias 1993: 91).

Establecer inferencias funcionales a partir de un estudio que explore únicamente la variabilidad tecnológica es insuficiente. En cambio, estudios experimentales que involucren la replicación del proceso de manufactura de los instrumentos, integrados con análisis de los rastros producidos por el uso, proporcionarán una visión mucho más dinámica de la variabilidad presente en los conjuntos artefactuales líticos.

A pesar de la abundante presencia de palas y/o azadas líticas en los contextos arqueológicos del NOA, las investigaciones de este tipo de instrumentos son escasas en Argentina. Sobre la funcionalidad asignada, las interpretaciones han sido diversas. En general, la discusión se ha basado en variables exclusivamente morfológicas (Boman 1992 [1908]; von Rosen 1924; Casanova 1933; Debenedetti y Casanova 1935; Latcham 1938; Márquez Miranda 1939, entre otros), aunque en los últimos años surgieron estudios enfocados en la interpretación de las huellas (Yacobaccio 1983; Ávalos 1998; Gastaldi 2001; Pérez 2003a, 2005a; Haber y Gastaldi 2006) que aportaron en la discusión sobre forma, función y estilo. Sin embargo, un tema relegado, y que ha señalado la necesidad de profundizar en la discusión, es el aspecto tecnológico involucrado en su manufactura.

En este contexto, ahora exploraremos la variabilidad de las palas y/o azadas líticas a través del análisis de conjuntos artefactuales recuperados de dos sitios de la Puna argentina. Este estudio es un primer acercamiento al problema planteado, para evaluar algunos aspectos de la tecnología involucrada en la manufactura de los instrumentos. Se realiza desde un enfoque técnico-morfológico y morfológico-funcional, y los resultados que obtengamos los integraremos a un programa experimental en curso y a los análisis de huellas de uso de las colecciones consideradas, a fin de aproximarnos a una explicación funcional y al significado de los patrones de esa variabilidad.

Es importante destacar que no se separaron "palas" y "azadas" como grupos tipológicos distintos a fin de no realizar una categorización a priori. En este sentido, todos los grupos tipológicos poseen una cuota de asignación funcional de los instrumentos para su clasificación y, en este caso en particular, es necesario profundizar en las investigaciones referidas a la experimentación de uso y la posterior determinación funcional de los instrumentos a través de análisis microscópicos de rastros producidos por el uso.

\section{* El caso de estudio}

El área de estudio comprende dos regiones de la Puna argentina: Antofagasta de la Sierra (prov. de Catamarca, Puna Meridional) y la cuenca del río Doncellas (prov. de Jujuy, Puna Septentrional) (Figura 1).

El depto. de Antofagasta de la Sierra, se ubica entre $25^{\circ}$ $50^{\prime}$ y $26^{\circ} 10^{\prime}$ Lat. S y $67^{\circ} 30^{\prime}$ y $67^{\circ} 10^{\prime}$ Long. $\mathrm{O}$, siendo su altitud promedio de 3450 y $3550 \mathrm{~m} . \mathrm{snm}$ (Olivera 1991a, 1991b). Constituye una de las cuencas hidrográficas endorreicas que posee cursos de aguas permanentes o semipermanentes, lo que origina vegas de buena pastura y ambientes relativamente aptos para el cultivo (Olivera 1991a). De este modo, es posible observar pastizales en los valles abrigados, en la ribera de las lagunas, vegas y márgenes de los cursos de agua. Este territorio presenta variaciones microambientales que permiten distinguir, tres sectores de muestreo: 1) fondo de cuenca; 2) sectores intermedios $y, 3$ ) quebradas de altura, los cuales se diferencian topográficamente ofreciendo distintos recursos (Olivera 1991a, 1991b). En estos sectores microambientales se han ubicado sitios arqueológicos relacionados a sistemas adaptativos formativos. Es importante destacar que dadas las diferencias topográficas y la oferta de distintos recursos, la muestra de sitios no es homogénea en 
su calidad y tipo de información, y tampoco la conservación del registro arqueológico es la misma.

Los sitios Casa Chávez Montículos (CCHM) y Real Grande 1 ( $\mathrm{RG} 1$ ), ubicados en los sectores de fondo de cuenca y quebradas de altura, respectivamente, fueron excavados sistemáticamente. Otros sitios solamente poseen información provista por recolección de superficie y/o sondeos diagnósticos (p.e., los del río Miriguaca, en los sectores intermedios). En muchos casos se observa una gran alteración causada por el saqueo (p.e., cementerios Casas Viejas 1 y 2 y Casa Chávez Lomas, ambos ubicados en el fondo de cuenca). Finalmente, existen sitios con arte rupestre que fueron exhaustivamente analizados por Podestá (198687, 1988, 1991; Podestá et al. 1991, entre otros).

De acuerdo al contexto, estos sitios cumplieron un rol diferente en el funcionamiento del sistema que Olivera (1987 Ms, 1991a, 1991b) denomina "sedentarismo dinámico". De este modo, en el fondo de cuenca, el sitio
CCHM corresponde a un campamento base residencial de actividades múltiples, de ocupación anual. En las quebradas de altura, el sitio RGi sería un puesto de caza y pastoreo de altura con ocupaciones periódicas, y en los sectores intermedios, Campo de las Tobas es un sitio a cielo abierto con petroglifos de grandes dimensiones.

De los sitios arqueológicos considerados por Olivera para la formulación de su modelo teórico, el sitio CCHM es el que se analiza en este trabajo. Se compone de 10 estructuras monticulares artificiales de dimensiones variables, dispuestas sobre una superficie de alrededor de $300 \times 300 \mathrm{~m}$, distribuidos en dos grupos sobre terrenos más elevados y alrededor de un espacio central deprimido (Olivera 1991b). Entre ellos, el Montículo 1 evidencia una ocupación larga y recurrente con, por lo menos, un claro episodio de abandono del sitio (Olivera y Nastri 1993). Hasta el presente, se realizaron excavaciones sistemáticas solo en los Montículos 1 y 4 . A partir de las excavaciones realizadas, se han detectado estructu-

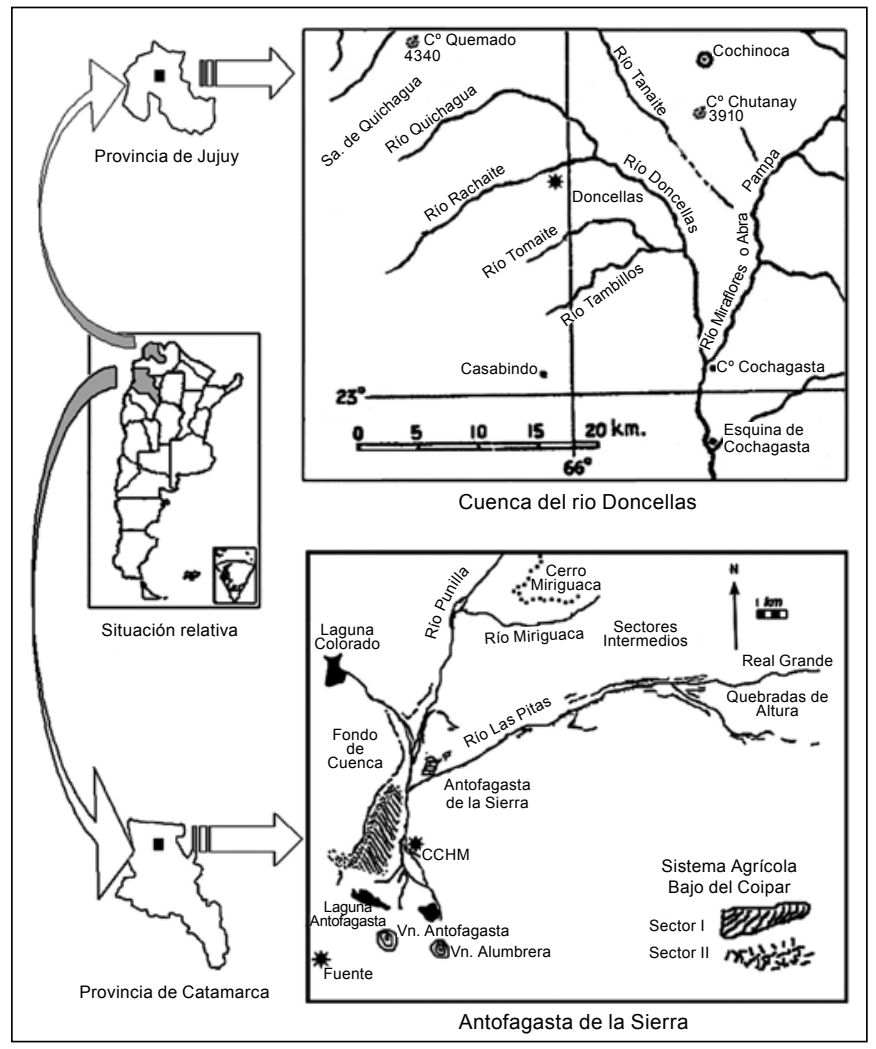

Figura 1. Ubicación del sitio Casa Chávez Montículos y del yacimiento de río Doncellas. 


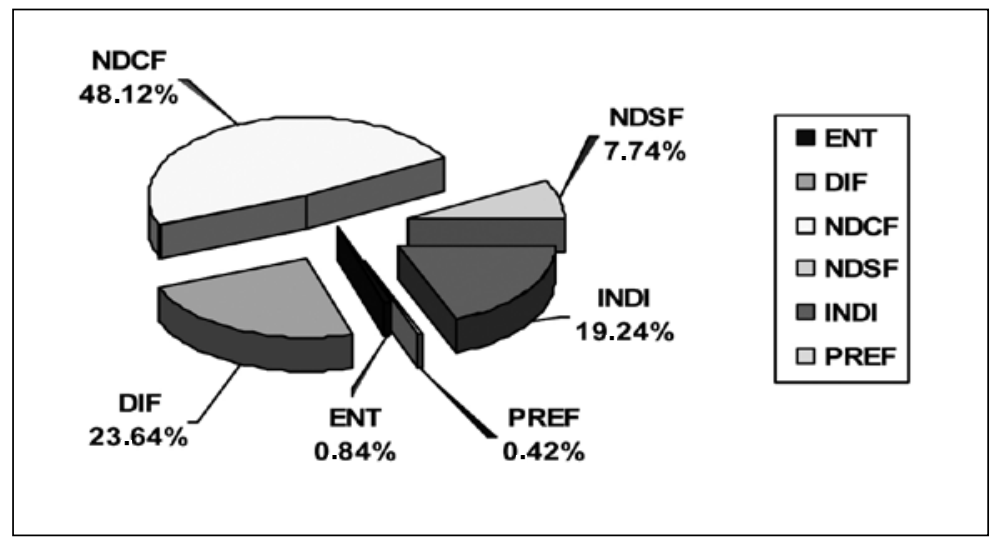

Figura 2. Casa Chávez Montículos. Distribución porcentual de palas y/o azadas por subgrupos tipológicos ( $\mathrm{n}=478)$.

ras de basural, de combustión, de cavado artificial (p.e. improntas de postes), sectores de talla lítica, evidencias de fabricación de cerámica y registro de procesamiento y consumo de camélidos, entre otras.

El registro arqueológico del sitio CCHM (Montículos 1 y 4) lo vincula con ocupaciones agropastoriles tempranas. Los fechados radiocarbónicos disponibles se encuentran entre $1530 \pm 70$ AP y $2120 \pm 60$ AP (Olivera y Vigliani 2000-2002: 464, Cuadro 2).

El material estudiado de CCHM (Montículos 1 y 4) se compone de cuatro instrumentos enteros y 474 fragmentados, de los cuales comprende 325 hallazgos en estratigrafía y 153 de la limpieza de perfiles y/o derrumbes, de estos últimos no se posee referencia exacta de su procedencia estratigráfica. Los mismos se encuentran distribuidos por subgrupos tipológicos como se detalla en la Figura 2. Al Montículo i corresponden dos piezas enteras y 340 fragmentadas mientras que, al Montículo 4 , corresponden dos piezas enteras y 134 fragmentadas.

\section{Cuenca del río Doncellas}

El área de la cual provienen los materiales considerados, se encuentra ubicada en el depto. de Cochinoca, prov. de Jujuy, aproximadamente a una altura de $3900 \mathrm{~m} . \mathrm{snm}$ y a $47 \mathrm{~km}$ de la localidad de Abra Pampa, punto de referencia en las cartas geológicas. Alfaro realizó excavaciones en las décadas de 1970 y 1980 en diversos sitios del área denominada por ella "Yacimiento del río Doncellas" o
"Cuenca del río Doncellas" (Alfaro 1988: 13). Los materiales recuperados, conocidos como Colección Doncellas INAPL, forman parte del inventario arqueológico del Instituto Nacional de Antropología y Pensamiento Latinoamericano, perteneciente a la Secretaría de Cultura de la Presidencia de la Nación. Cabe destacar que, a diferencia de otras colecciones, se caracteriza por ser producto de trabajos de investigación, revistiendo de esta manera un potencial valor para su estudio (Pérez de Micou 1998). Como tal, la colección es clasificada, documentada y analizada teniendo en consideración el sesgo en la información que presenta toda colección depositada en museos o instituciones.

Dentro del área geográfica definida por Alfaro de Lanzo$n e^{2}$ existen:

“...una serie de sitios relacionados entre sí temporalmente a través de sus estilos cerámicos, sus manifestaciones de arte rupestre y la explotación de ciertos recursos naturales (agricultura, pastoreo de auquénidos, explotación de la sal)..." (Alfaro y Suetta 1976: 2; Alfaro 1988: 13).

Y también por el ambiente físico, los sitios se escalonan a lo largo de la cuenca del río Doncellas, que constituye el accidente geográfico más significativo del área.

\footnotetext{
2 “...rectángulo imaginario de unos $35 \times 25 \mathrm{~km}$ de lado, entre los $22^{\circ} 45^{\prime}-23^{\circ}$ de Lat. Sy $66^{\circ}-66^{\circ} 20^{\prime}$ de Long. O” (Alfaro y Suetta 1976: 2; Alfaro de Lanzone 1988: 13).
} 


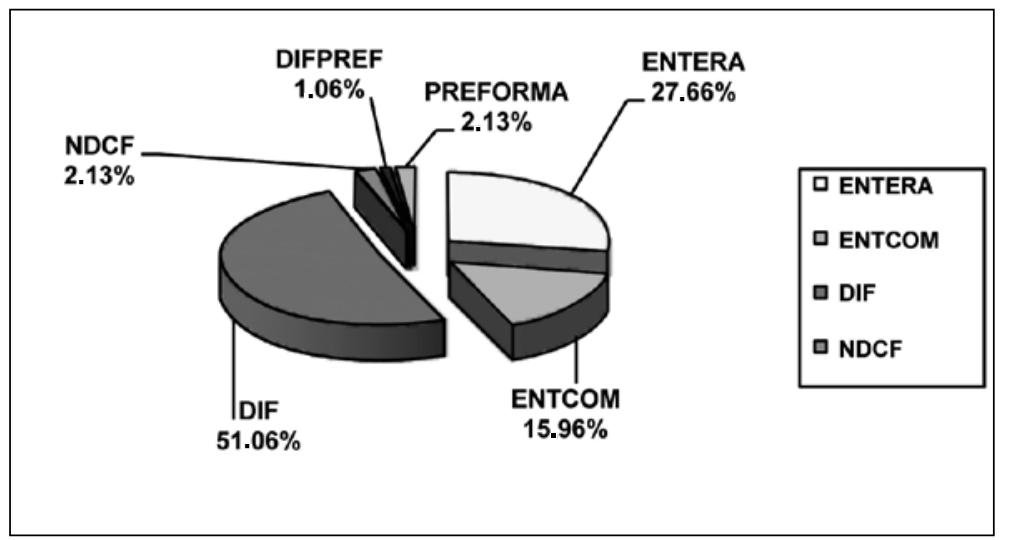

Figura 3. Colección Doncellas. Distribución porcentual de palas y/o azadas por subgrupos tipológicos $(n=94)$.

Las investigaciones de Alfaro de Lanzone fueron realizadas en diferentes sectores del yacimiento: Poblado, Farellones, Andenes y Acequias, Estructura Escalonada, Círculos Hundidos, así como también en diferentes cuevas y aleros de la zona, como: Tajuera, Queta, Quebrada Ancha, Cueva del Felino, Sayate, Sorcuyo y Pulaira; aunque centró sus excavaciones en el Poblado "...cuyos recintos no habían sido excavados sistemáticamente..." (1988:31), el cual dividió según su ubicación en relación al río Doncellas en: "Margen derecho del corte geológico": S.E.R. 1, S.E.R. 2 (Sector entrada, Recintos 1 y 2 , respectivamente) y varios sectores con recintos asociados, y "Margen izquierdo del corte geológico": S.E.I. R 1 y S.E.I. R 2 (Sector entrada izquierda, Recintos 1 y 2 , respectivamente).

Se recuperó evidencia arqueológica lítica, cerámica y de metal, así como también artefactos de madera, hueso, textiles, cestería, calabazas, y restos óseos humanos. Existe registro de arte rupestre en diversos sitios, además de relevamiento de estructuras arquitectónicas de diversa índole. Estos indicadores permitieron identificar diferentes áreas de trabajo y de actividades ceremoniales del yacimiento, a partir de lo cual Alfaro de Lanzone concluyó que la ocupación correspondió a un “...ciclo habitacional corto temporalmente pero repetido cíclicamente..." (1988: 135).

El asentamiento principal fue definido por Alfaro de Lanzone como un "poblado prehispánico", identificando diferentes áreas de utilización con actividades específicas en los recintos excavados, las cuales denominó: S.E.R.
1: "cocina", Sector 3 - Recinto 2: "taller de un lapidario", Sector 2 - Recinto 1: "taller de tejedores" y Sector 2 - Recinto 4: "depósito de material lítico". Por otro lado, definió a la Estructura Escalonada como un "monumento ceremonial" y a la Cueva de Tajuera como un "sitio ceremonial”, ambos relacionados entre sí (1988: 134-135).

De acuerdo acon los fechados radiocarbónicos disponibles, el área arqueológica de la cuenca del río Doncellas se ubica cronológicamente entre $740 \pm 50$ y $310 \pm 50 \mathrm{AP}$ (Alfaro de Lanzone 1988: 152-154).

En este trabajo, la muestra analizada de la Colección Doncellas consta de 94 piezas, de las cuales el $45.75 \%$ corresponde a piezas enteras y el $54.25 \%$ restante a piezas fragmentadas, distribuidas por subgrupos tipológicos como se detalla en la Figura 3. Los sitios considerados corresponden a diversos sectores y recintos del Poblado, Farallones y Círculos Hundidos. Además de diversas cuevas y aleros: Cueva del Felino, Cueva de Tajuera, Pulaira, Quebrada Ancha, Queta, Sayate y Sorcuyo. Comprende hallazgos en estratigrafía y de recolección de superficie, distribuidos por sitio según detalle presentado en la Figura 4. Lamentablemente, de un número considerable de ellos se desconoce la procedencia exacta del sitio al cual pertenecen, dado que los rótulos identificatorios solo dicen "Colección Doncellas".

Es importante destacar que, si bien la muestra de Antofagasta de la Sierra $(n=478)$ es la más numerosa, también es la más incompleta ya que se registra un alto grado de 


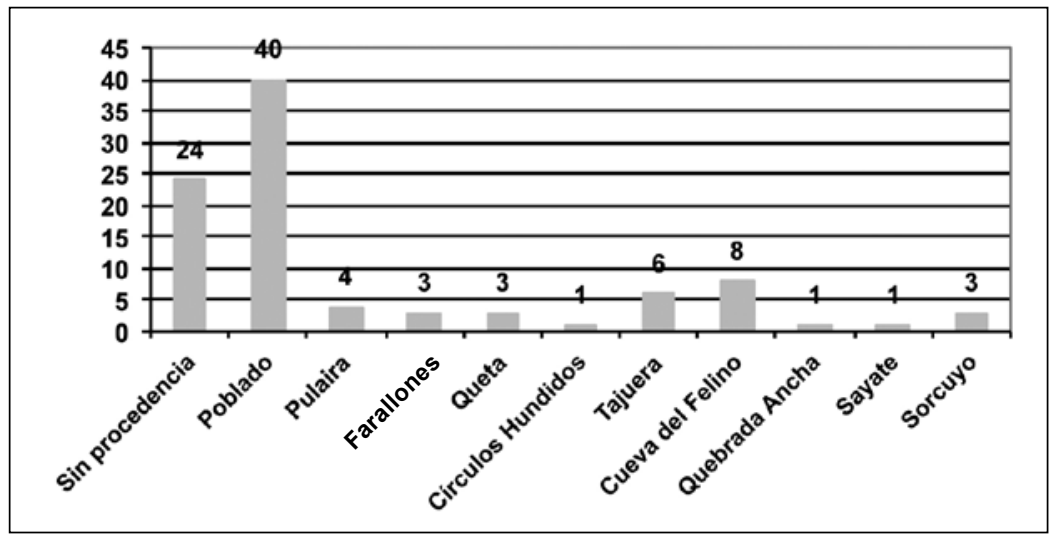

Figura 4. Colección Doncellas. Distribución de palas y/o azadas por sitio $(n=94)$.

fragmentación (99.16\%), habiendo solo cuatro instrumentos enteros. En cambio, la correspondiente a la Colección Doncellas no es tan numerosa $(n=94)$, pero tiene un importante porcentaje de piezas enteras $(45.75 \%){ }^{3}$

\section{* Metodología}

El estudio se encaró a través de diversas líneas de análisis:

1) Análisis técnico-morfológico y morfológico-funcional de la evidencia arqueológica y de la colección experimental de referencia.

2) Implementación de un Programa Experimental tendiente a la replicación (sensu Nami 1992) y uso de los artefactos.

3) Análisis de las huellas de uso presentes en artefactos arqueológicos y experimentales. Dado que la metodología y

\footnotetext{
3 Al respecto, es importante tener en cuenta que la diferencia observada en la representatividad de piezas enteras entre ambas colecciones consideradas, probablemente se deba a las técnicas de recolección implementadas. En el caso de la Colección Doncellas, se desconoce en profundidad el método de excavación, recolección, rotulado y depósito de los materiales, por lo tanto, no es posible realizar inferencias relacionadas con el estado de fragmentación del material, aunque resulta extraño que, tratándose de un yacimiento en el cual Lanzone determinó diversas áreas de actividad, no se registren desechos de talla de la materia prima utilizada en la manufactura de palas y/o azadas.
}

los resultados de los análisis ha sido descrito en diversas publicaciones, solo se reseñan brevemente, con especial énfasis en algunos aspectos de la primera línea de análisis, ya que conciernen a lo discutido en este trabajo.

El análisis técnico-morfológico y morfológico-funcional se encaró siguiendo los lineamientos propuestos por Aschero $(1975,1983)$ adecuándolos a las características particulares del material (Pérez 2003a). Para el registro de variables o estados de atributos se confeccionó una ficha técnico-morfológica basada en aquella ideada por Aschero (1983). Para el análisis se siguieron cuatro pasos: 1) segmentación del conjunto; 2) orientación, ilustración y segmentación descriptiva de los instrumentos; 3 ) descripción técnico-morfológica y morfológico-funcional, y 4) clasificación de subgrupos tipológicos.

Las piezas fueron divididas en dos secciones: cuerpo y pedúnculo, a su vez, se realizó la segmentación descriptiva (sensu Aschero 1983, Apéndice B), considerando aspectos que pudieran dar un indicio certero de la ubicación del fragmento en relación a la pieza entera, tales como forma general del fragmento y borde, cambio en la curvatura del borde o evidencias macroscópicas de pulido y/o estrías.

Para la descripción técnico-morfológica y morfológicofuncional se consideraron las siguientes variables: a) forma general del cuerpo y pedúnculo; b) características técnicas generales; c) características del contorno y caras; d) descripción de las fracturas principales, y e) segmentación descriptiva. 
Los criterios utilizados para la clasificación diferencial de los subgrupos tipológicos se basaron en la segmentación descriptiva detallada anteriormente. Los subgrupos tipológicos incluyen: piezas enteras manufacturadas por lascados en todo su perímetro (ENT), piezas enteras con manufactura combinada, por pulido en segmento apical y por lascado en el resto del perímetro (ENTCOM), fragmentos diferenciados en los cuales es posible determinar a qué parte de la pieza entera corresponden (DIF), fragmentos no diferenciados con filo (NDCF), fragmentos no diferenciados sin filo (NDSF), fragmentos diferenciados de preformas (DIFPREF), piezas enteras en proceso de manufactura (PREFORMA) y fragmentos indiferenciados (INDI). Se consideraron como piezas "enteras" todas aquellas que, aunque estén fracturadas, representan más del 75\% de la pieza total, y dentro de la categoría "fragmentos diferenciados" se encuentran aquellos fragmentos que representan menos del $75 \%$ y que por sus características evidencian a qué parte de la pieza entera pertenecen (p.e., filo apical, filo lateral del cuerpo, pedúnculo, inflexión cuerpo-pedúnculo).

Los resultados obtenidos del análisis técnico-morfológico del conjunto de palas y/o azadas líticas de CCHM fueron aplicados, entre otras cosas, a la elaboración de un programa experimental, dirigido a la realización de diversas actividades relacionadas con las diferentes etapas por las cuales pasaron los artefactos: a) aprovisionamiento y selección de la materia prima; b) replicación (sensu Nami 1992) de artefactos con el fin de obtener una colección de referencia; c) experimentación de enmangue, $y d$ ) experimentación de uso. La finalidad era obtener una colección experimental para utilizarla en tareas que pudieron haber sido realizadas con los instrumentos arqueológicos estudiados, y el posterior análisis de los rastros resultantes de su utilización (Pérez 2003a, 2003b).

De este modo, los instrumentos replicados fueron formatizados por lascados de retalla y retoque bifacial marginal, manufacturados por percusión directa, siguiendo las pautas de la evidencia arqueológica recuperada de CCHM. Los instrumentos replicados fueron enmangados para su utilización (Pérez 2004b), la cual se llevó a cabo en los campos de cultivo prehispánicos denominados Bajo del Coypar I - Sector 1, en las inmediaciones del sitio CCHM. Los instrumentos experimentales fueron utilizados en dos modos de acción (cavar y picar) en forma separada.
Las pruebas de uso se encararon con interrupciones de 500,1000 y 1500 golpes o penetraciones en el sedimento, controlando diversas variables consideradas de interés (Pérez 2004a). Teniendo en cuenta que las características del material de contacto inciden directamente en la formación de rastros, se realizaron los análisis pertinentes ${ }^{4}$ para conocer las características del mismo.

El análisis de los rastros producidos por el uso se efectuó en dos colecciones, la arqueológica y la experimental de referencia. Las observaciones fueron realizadas mediante el uso de lupa binocular (stereo microscope) Olympus VMZ (BH2-PM-6), con magnificaciones entre 40x y $160 x, y$ luz externa oblicua (con incidencia a $45^{\circ}$ respecto al plano de la pieza). Por lo tanto, los rastros observados se refieren solo a esta escala de análisis, la cual fue dirigida a determinar el proceso de formación y las diferentes velocidades de aparición y desarrollo de los rastros. Posteriormente, se procedió a la comparación analógica de los rastros de utilización y las características formales entre el material arqueológico y el experimental. Finalmente, se realizó un estudio tendiente a establecer las relaciones entre el comportamiento de uso y los rastros presentes en la colección experimental (Pérez 2003a, 2005).

Por otra parte, el método de trabajo para la clasificación de las rocas utilizadas en la manufactura de los instrumentos se basó en el análisis geológico y petrográfico de materiales provenientes de ambas regiones, y se efectuó a partir de una descripción macroscópica y caracterización microscópica. Para el análisis geológico se realizó una descripción y caracterización de los macizos rocosos cercanos a los sitios, se analizaron diversas variables relacionadas con las discontinuidades y se realizó el estudio de la matriz rocosa. Las variables estudiadas a nivel de matriz rocosa fueron: el tipo de matriz, el grado de meteorización y el grado de resistencia. Con respecto a las discontinuidades se analizó la orientación, el espaciado, la continuidad, y el tamaño y la forma de los bloques resultantes de la degradación del afloramiento. Posteriormente, se realizó el análisis petrográfico sobre cortes

\footnotetext{
4 Se realizaron análisis granulométricos, ensayos para determinar el grado de compactación y el grado de humedad, así como también ensayos químicos tendientes a conocer tanto la presencia/ ausencia de materiales orgánicos, como los contenidos de componentes ácidos del suelo (Pérez 2003a).
} 
delgados a fin de caracterizar con mayor detalle el material y proceder a su clasificación (Pérez et al. 2006). Las muestras de materias primas analizadas provienen del Recinto Ac, correspondiente a uno de los sectores del Poblado (Colección Doncellas) y del Montículo I (CCHM).

\section{* Resultados}

\section{Técnica de manufactura}

La formatización de la muestra total de instrumentos de CCHM se realizó por medio de lascados de retalla y retoque bifacial marginal en todo su perímetro (Figura 5), manufacturados por percusión directa (Pérez 2003a, 2006). En algunos sectores de los filos se advierte la ausencia de trabajo de retalla y/o retoque, manteniendo los bordes naturales de las lajas.

Por otro lado, el conjunto artefactual de la Colección Doncellas presenta variabilidad en la técnica de manufactura aplicada para obtener el producto final. Encontramos instrumentos que fueron formatizados con la misma técnica utilizada en CCHM, es decir, lascados de retalla y retoque marginal en todo su perímetro, siendo su manufactura por percusión directa. Mientras que, en otros instrumentos, la formatización se realizó por pulido (Figura 6) en la parte correspondiente al filo activo (segmento apical) y por técnica de lascados de retalla y retoque marginal bifacial en el resto del perímetro (segmentos laterales del cuerpo, inflexión cuerpo/pedúnculo y pedúnculo), sien-

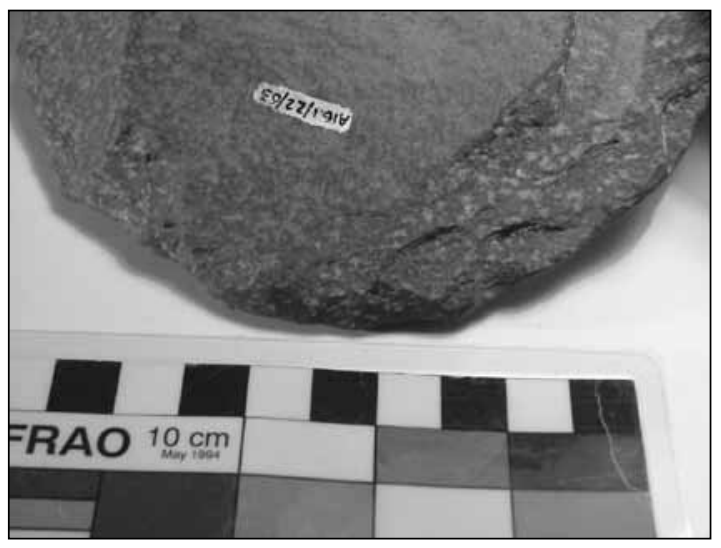

Figura 5. Segmento apical: Técnica de manufactura por lascado. do su manufactura por percusión directa. Por último, se advierte que en un número considerable de casos los instrumentos no presentan técnica alguna de manufactura en lo que se refiere al segmento apical, manteniendo el borde natural de la laja (Pérez $2005 \mathrm{Ms}$ ).

De este modo, el tratamiento del segmento apical (Serie Técnica, sensu Aschero 1975, 1983), presenta importantes variaciones internas dentro del conjunto analizado de la Colección Doncellas (Pérez $2005 \mathrm{Ms}$ ). El 18.39\% de los casos ( $\mathrm{n}=87$, correspondientes al Segmento apical) corresponde a lascados bifaciales, mientras que $8.05 \%$ del mismo número de casos corresponde a lascados unifaciales, manteniendo una de las caras en estado natural, es decir, sin técnica de manufactura. Por otro lado, dentro de las piezas en las cuales se practicó formatización por pulido, encontramos combinaciones. En un $22.99 \%$ de los casos se observa manufactura por pulido bifacial, mientras que en $35.63 \%$ de ellos el pulido del bisel fue unifacial. En este último caso, en la cara opuesta a la pulida, en $25.29 \%$ el filo fue regularizado por lascados de retoque marginal y $10.34 \%$ se mantiene en estado natural (Figura 7).

En resumen, en el conjunto artefactual de la Colección Doncellas, $26.44 \%$ de las piezas fueron manufacturadas por técnica de lascado (en algunos casos combinado con bordes naturales), 58.6.2\% por técnica de pulido (bien en forma bifacial o combinando con una de las caras por técnica de lascado o borde natural), y $14.94 \%$ corresponde a instrumentos en los cuales no se realizó manufactura alguna en el segmento apical.

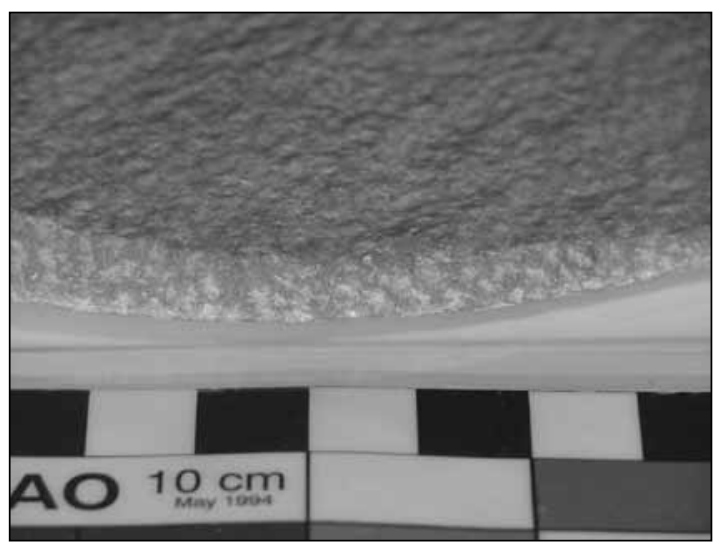

Figura 6. Segmento apical: Técnica de manufactura por pulido. 


\section{Caracterización de la morfología de cuerpos}

En la muestra correspondiente a CCHM, la forma general de los cuerpos es semielíptica (Figura 8a), advirtiéndose que esta morfología mantiene el mismo patrón cuando se observan los fragmentos diferenciados (DIF), especialmente en aquellos con dimensiones tales que dan cierta representatividad a la pieza entera, siendo la forma geométrica de los filos convexa.
En los instrumentos de la Colección Doncellas, la forma general predominante de los cuerpos es trapezoidal en $75.60 \%$ de los casos $(n=41$, tomando en consideración las piezas enteras correspondientes a los subgrupos tipológicos ENT y ENTCOM) (Figura 8b y c), en detrimento de las formas cuadrangulares y circulares irregulares, que tienen $7.32 \%$ y $4.88 \%$ de representación, respectivamente (Figura 9 a, by c), mientras que $12.20 \%$ corresponde a formas indiferenciadas ya que se presentan muy irregula-

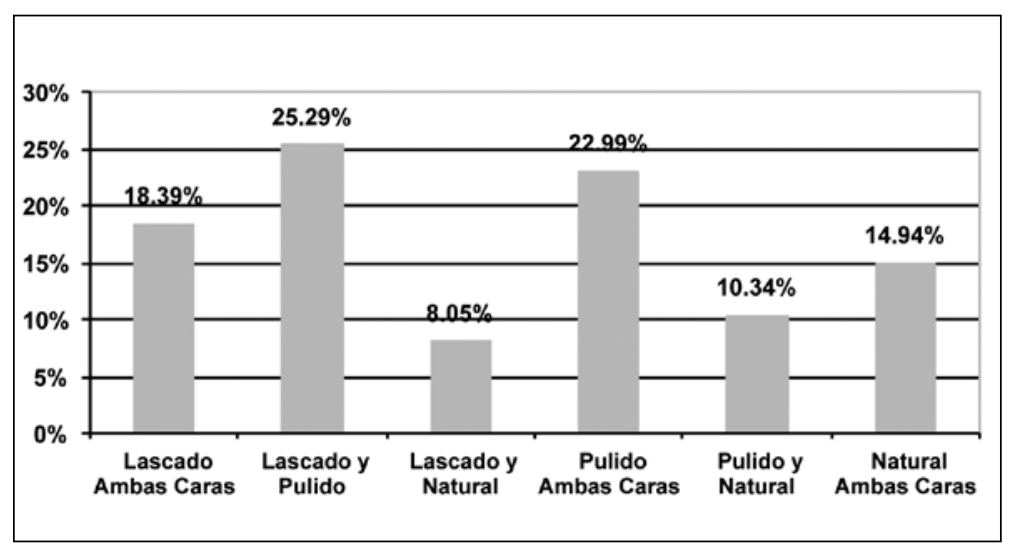

Figura 7. Colección Doncellas. Distribución porcentual de piezas según técnica de manufactura aplicada en el segmento apical $(n=87)$.

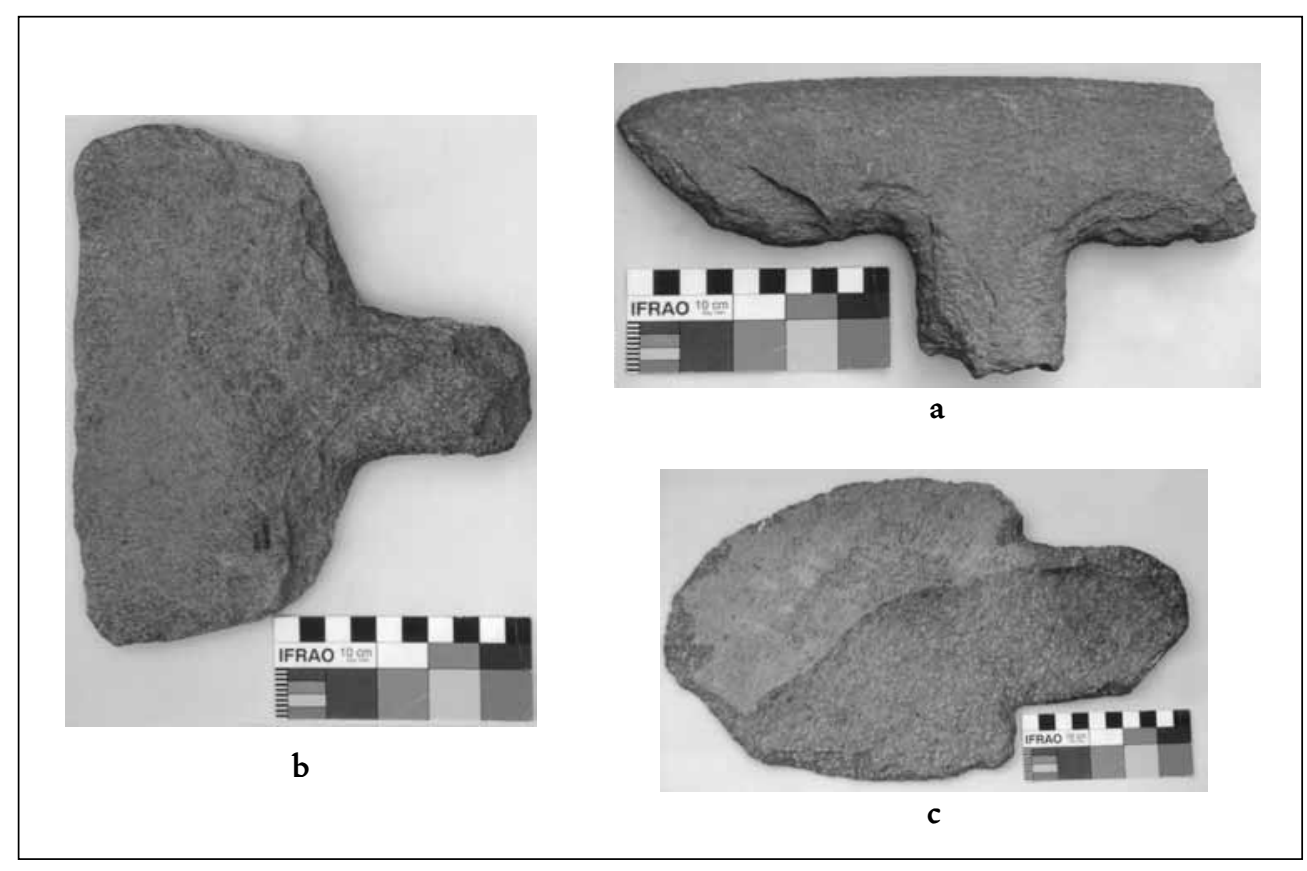

Figura 8. Morfología general del cuerpo: a) semielíptica; b y c) trapezoidal. 
res, conformando lo que denomino "artefactos atípicos". La forma geométrica predominante de los filos es recta.

Tomando en consideración el módulo longitud/ancho de los cuerpos de las piezas, en CCHM la longitud siempre es mayor al ancho, mientras que en la Colección Doncellas esta relación es a la inversa. Al mismo tiempo, hay una tendencia de módulos más grandes en aquellas piezas que no tienen el bisel pulido.

\section{Caracterización de la materia prima}

En base a los análisis geológicos, ambas muestras tienen en común que presentan:

“...formas tabulares o laminares según la clasificación de Zingg (Pettijohn 1980: 6, fig. 25) [...] se caracterizan por presentar largos y anchos mucho mayores que el espesor [...] la superficie de las discontinuidades es casi lisa y el tamaño del clasto correspon- de a bloque según la clasificación de Udden-Wentworth (Boggs 1992)" (Pérez et al. 2006: 221).

Las condiciones climáticas de la Puna favorecen la intensa meteorización física provocando la degradación de rocas de diverso origen y edad, lo que permite la formación de depósitos coluviales. En Antofagasta de la Sierra, los bloques provienen de la degradación de la Formación Incahuasi, de edad Cuaternaria. En el área de Doncellas, las rocas volcánicas que presentan formas tabulares o laminares corresponden a la Formación Vicuñahuasi, ubicada muy cerca a los sitios arqueológicos aquí tratados. Está integrada por lavas y brechas autoclásticas de edad Terciaria y son el resultado de la fluidez de los componentes mineralógicos de la pasta. En ambas Formaciones, estas rocas son aptas para ser utilizadas en la manufactura de palas y/o azadas y se diferencian de otras variedades de materias primas utilizadas en la ergología lítica de los sitios. Esquistos, pizarras, basaltos o andesitas, informal-

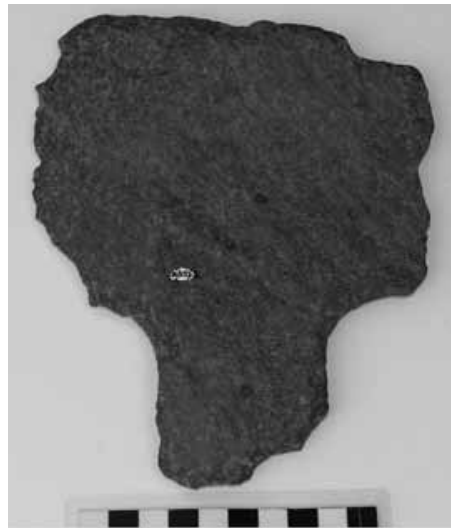

a

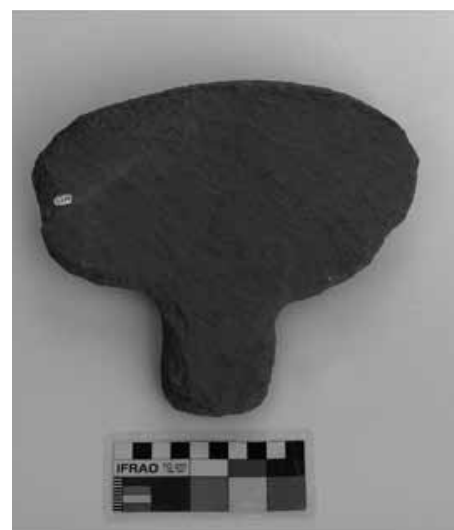

b

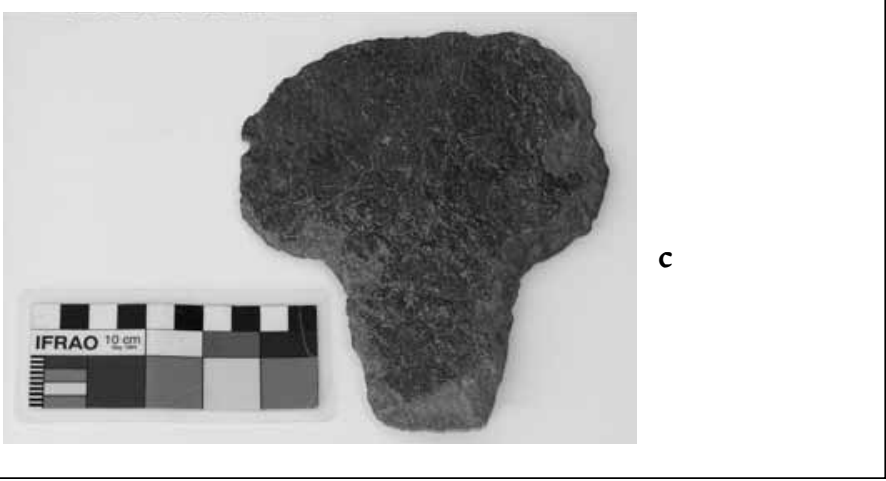

Figura 9. Morfología general del cuerpo: a) cuadrangular; b y c) circular irregular. 
mente denominadas "lajas", proceden del mismo sistema de fracturamiento aunque tengan distinto origen y edad.

De acuerdo a los análisis petrográficos, ambas muestras corresponden a rocas volcánicas que se clasifican entre basaltos y andesitas y se diferencian a nivel de cristalinidad y textura de las pastas. La muestra correspondiente a CCHM fue clasificada como andesita piroxénica, mientras que la de la Colección Doncellas fue clasificada como basalto andesítico (Pérez et al. 2006).

\section{* Discusión}

Los análisis realizados dieron como resultado una gran variabilidad entre ambos conjuntos artefactuales, la cual queda evidenciada en la técnica de manufactura, la morfología general de los instrumentos y la materia prima empleada en su manufactura. Ahora bien, esta variabilidad en la técnica de manufactura ¿involucra mayor o menor esfuerzo o destreza en su realización?, irequiere mayor o menor tiempo para efectuarla?, iresponde a elecciones estilísticas o a diferencias funcionales vinculadas con actividades específicas? Para responder estas preguntas, es necesario evaluar el costo de manufactura en términos de habilidad del artesano y el tiempo involucrado para obtener el producto final. Para ello, es necesario profundizar el programa experimental en marcha, tendiente a la replicación de instrumentos manufacturados por técnica de pulido, a fin de generar modelos explicativos acerca del problema planteado. En este sentido, es importante destacar que en la práctica de replicación de artefactos por técnica de lascado en todo su perímetro, la formatización requirió destreza por parte del tallador, involucrando una importante inversión de trabajo para su producción, especialmente en la etapa de confección de las zonas del pedúnculo e inflexión cuerpo/pedúnculo en función de la necesidad del enmangue.

Asimismo, dentro del conjunto artefactual de la Colección Doncellas, se cuenta con piezas clasificadas como preformas de palas y/o azadas, las cuales evidencian las posibles etapas de reducción del borde natural de la laja a fin de reducir su espesor por medio de lascados y, de este modo, podrían estar en condiciones para la regularización final del borde por medio de pulido. Una de las características que sobresale en los conjuntos artefactuales analizados, es la forma y dirección de los lascados de formatización, la cual se presenta en los instrumentos manufacturados por percusión como "escamoso irregular" (sensu Aschero 1983), mientras que en los filos apicales de algunas de las preformas fue "paralelo laminar irregular".

Ávalos (1998), en análisis efectuados en materiales similares a los nuestros, provenientes del sitio Ojo de Agua (Ojar) (Casabindo, Puna de Jujuy), identificó dos técnicas de manufactura para la producción de artefactos: 1) técnica de percusión y, 2) técnica de "afilado", realizada en dos pasos:

"Primero, la parte distal de los instrumentos fue regularizada con retoques más finos, generando filos rectos [...]. Segundo, fueron afilados por medio de la abrasión sobre superficies planas, haciendo desaparecer los negativos de lascado" (Ávalos 1998: 295).

Dentro de los patrones observados como resultado de esa actividad, Ávalos menciona que:

"Las estrías tienen forma de surcos anchos y cóncavos, paralelos entre sí. La orientación puede ser oblicua o paralela al eje morfológico [...]. Esta forma de estrías solamente se presenta en la superficie del filo y no en otra parte del instrumento" (1998: 296).

De esta manera, distingue "huellas de manufactura" de "huellas de uso", afirmando que las características y la orientación que presentan las estrías, así como los ángulos de los filos, indican que fueron producidos durante la manufactura de los instrumentos y no como resultado de la utilización de los mismos.

Estas evidencias permitirán guiar los trabajos experimentales en curso, implementando la manufactura por pulido para la producción de filos como los observados en los segmentos apicales de los conjuntos estudiados de Doncellas. La realización de experimentos controlados y el análisis de huellas de uso presentes en las piezas arqueológicas y experimentales de referencia, ayudarán a identificar y aislar indicadores que permitan diferenciar el pulido intencional del micropulido producido por el uso, es decir, el que surge de la manufactura del bisel que resulta como consecuencia de la utilización de los instrumentos. En principio, aunque los estudios están en proceso, se observa que los rastros por uso, como por ejemplo, estriaciones, se presentan en forma perpendicular al filo activo en aquellas piezas que 
presentan pulidos y filos redondeados con un alto grado de desarrollo. Es necesario continuar con los análisis para observar en las piezas en que el grado de desarrollo de estos últimos rastros se encuentra poco avanzado, cuales son las características de las estrías, como por ejemplo, su morfología y orientación respecto del filo apical.

En cuanto a la morfología general de los artefactos, el análisis técnico-morfológico permitió identificar una gran variabilidad en la forma general de los cuerpos en las piezas de ambas colecciones, mientras que los pedúnculos guardan un mismo estándar morfológico. Si bien se han registrado algunos casos en que hubo reactivación de filos, el estado de las investigaciones aún no permite afirmar su incidencia en la modificación de la morfología del cuerpo de los artefactos, salvo en pocos ejemplares que son considerados "atípicos" o muy irregulares (ver Figura 9). En términos generales, las dimensiones de los artefactos cuya morfología es trapezoidal (ver Figura 8c), no son comparables a aquellas de los artefactos que ostentan morfología semielíptica (ver Figura 8a). No obstante, los datos que arrojen los análisis de los desechos de producción, tanto de la colección arqueológica como de la experimental, revisten gran importancia para la interpretación de la variabilidad de los artefactos, ya que pueden brindar evidencias (tales como estrías y pulidos característicos del uso) del proceso de reactivación de los filos. En este trabajo no se incorporaron ya que todavía se encuentran en proceso de análisis.

En otro ámbito, el espesor de las piezas constituye una variable que se debe profundizar en el análisis. En principio, las evidencias indican una tendencia a menores espesores del sector apical, respecto de las piezas enteras, en aquellas que no tienen el bisel pulido. Es probable que, con la manufactura por pulido, se buscara adelgazar el borde natural de la laja y obtener filos con ángulos más agudos para realizar actividades que así lo requerían. Esta hipótesis nuevamente nos remite al programa experimental en curso, en este caso relacionado con la experimentación de uso en una mayor diversidad de actividades.

Siguiendo con los espesores de las piezas, en ambas colecciones se evidencia, en términos generales, una tendencia a espesores mayores en la parte correspondiente al pedúnculo, especialmente en el sector de inflexión cuerpo/pedúnculo en relación a las piezas enteras (Pérez
2005 Ms y 2006), lo cual podría deberse a la búsqueda funcional del instrumento, es decir, aumentar la fuerza ejercida, lograr mayor eficacia en la labor llevada a cabo $y$ otorgarle un refuerzo al instrumento ante eventuales fracturas (Pérez 2004a y 2004b).

Finalmente, los soportes utilizados en la manufactura de palas y/o azadas de ambas colecciones fueron "lajas", y la materia prima utilizada corresponde a rocas volcánicas que se clasifican en basaltos y andesitas y se diferencian a nivel de cristalinidad y textura de las pastas. Sobre esta variabilidad, Gastaldi, basada en análisis microscópicos de cortes delgados efectuados en distintas canteras, y en palas provenientes del sitio Tebenquiche Chico (Antofagasta de la Sierra, Catamarca) define la materia prima utilizada en su manufactura:

“...como basalto-andesita, ya que posee características que la asocian a basalto o a andesita. No podemos establecer fehacientemente qué tipo de andesita o qué tipo de basalto es ya que a nivel óptico no se puede determinar; se necesitan análisis geoquímicos para establecer las diferencias" (2001: 43).

Por otro lado, Aschero y colaboradores (2002-2004), para unificar la denominación de las materias primas utilizadas para la talla de artefactos en la microrregión de Antofagasta de la Sierra, proponen llamar a dicha materia prima "vulcanita" (Vc8).

La caracterización geológica del área de estudio y la descripción petrográfica de la materia prima es crucial para discutir la variabilidad de los conjuntos líticos, aunque dadas las características de este tipo de roca se considera necesario incluir análisis como los de Gastaldi. Por otro lado, una muestra estadística mayor, brindará información relevante acerca de la variabilidad en la materia prima utilizada en la manufactura de palas y/o azadas. En este sentido, además de los análisis aquí presentados, se realizó el análisis petrográfico en una muestra recolectada en la fuente de aprovisionamiento localizada por Escola (1990-92, 1991) en el margen izquierdo de las coladas de los volcanes Antofagasta-La Alumbrera (Los Negros), distante entre 5-7 km del sitio CCHM. La misma fue clasificada como basalto andesítico (Pérez et al. 2006). También, Elías y colaboradores (2006 y 2007) realizaron análisis petrográficos en muestras provenientes de Campo Cortaderas (Antofagasta de la Sierra, Catamarca) y se encuentran en 
proceso de análisis otras muestras también provenientes de este departamento (Elías com. pers. 2008).

\section{* Consideraciones finales}

Al iniciar la investigación eran muchas las preguntas formuladas en referencia a estos artefactos: si eran herramientas para cavar, cual era la función específica que cumplían; si eran instrumentos para la agricultura o respondían a actividades diferentes también derivadas de cavar, como por ejemplo, preparación de tumbas, pozos de almacenamiento; o tareas de mantenimiento del campamento base; o bien, si estaban relacionadas con prácticas forrajeras.

Los análisis técnico-morfológicos, experimentación y análisis de huellas de uso, arrojaron información que permite asegurar que las palas y/o azadas líticas eran instrumentos para trabajar la tierra, implicando una amplia gama de tareas posibles de realizar, que incluyen tanto aquellas relacionadas con la agricultura como las tendientes a responder a las necesidades de un campamento base, como es el caso del sitio CCHM. Esto implica el empleo de los instrumentos con diferentes modos de acción (p.e., picar, cavar, levantar, barrer, zapar, etc.), que son necesarios para realizar las tareas antes mencionadas, produciendo rastros de desgaste diferenciales.

Como ya se mencionó, algunas de las preguntas están dirigidas a conocer y explicar los cambios en la organización tecnológica de las sociedades que habitaron una región muy importante del NOA, la Puna. Para ello, es necesario calibrar las dimensiones del cambio temporal y espacial, así como también su significado dentro del contexto cultural.

Los conceptos de "conservado" y "expeditivo" caracterizan a las dos estrategias tecnológicas más utilizadas para explicar el producto material que resulta de su implementación. El comportamiento relacionado con la selección de esas estrategias fue atribuido a diversas variables y se basa en la evaluación de los costos involucrados en el uso eficiente de tiempo, energía y recursos, como por ejemplo: disponibilidad de materia prima, localización de las fuentes de aprovisionamiento, estrés temporal, manufactura, transporte y movilidad, variando el énfasis puesto en cada variable (Pérez 2003a y 2010).
En general, los estudios sobre tecnología lítica de distintas épocas coinciden en señalar el cambio observado en la inversión de trabajo invertido en la formatización de los artefactos, el cual evidencia una menor inversión de tiempo y energía para obtener el producto final en los conjuntos artefactuales de momentos tardíos. Esta tendencia se observa a nivel regional en la porción meridional de los Andes Centro Sur. En este sentido, Carrasco (2003, 2004) al comparar la ergología lítica de sitios tempranos (Arcaico Tardío y Formativo) y tardíos (Intermedio Tardío y Tardío) de la localidad de Caspana en Chile, sostiene que en momentos tardíos se estaría optando por una estrategia más expeditiva u oportunística, con una baja inversión de trabajo en los artefactos, estando la formatización condicionada por la actividad a realizar, resaltando la importancia del costo de producción de los instrumentos. Este autor, considerando sitios de los períodos Intermedio Tardío y Tardío del Salar de Atacama y del Loa Superior, concluye que la variabilidad artefactual de los artefactos de molienda se asocia a las diferencias funcionales de los yacimientos (Carrasco 2003).

Méndez, basándose en materiales líticos relacionados a la red vial incaica del Alto Loa, también habla de conductas expeditivas en momentos tardíos, sosteniendo que:

"...las decisiones tecnológicas involucraron el uso de aquello inmediatamente disponible [...]. Estas decisiones también se manifestaron a través del desarrollo de instrumentos muy informales, con formas situacionales y de escasa inversión laboral y rápidas tasas de descarte" (2007: 53).

$\mathrm{Al}$ referirse a los instrumentos como los que nos ocupan en este trabajo, Méndez menciona que “...las palas constituyen un ejemplo de integración de soluciones tecnológicas más conservadas a un panorama donde dominó largamente la expeditividad" (2007:54).

Igual tendencia interpretativa podemos encontrar para la microrregión Antofagasta de la Sierra. Hocsman (2006) en su análisis del cambio en la tecnología lítica durante la transición de cazadores recolectores a sociedades agropastoriles, señala que allí existe una tendencia a invertir menor tiempo y energía en la producción de artefactos tallados con "preponderancia relativa del trabajo no invasivo con el paso del tiempo" (2006: 68). Por su parte, Escola sostiene que el componente tecnológico del sitio $\mathrm{CCHM}$, asignable a sociedades agropastoriles tempranas 
(Formativo), se refiere a estrategias expeditivas con "...una planificación orientada a minimizar el esfuerzo que pudiera invertirse en la producción de instrumentos" (2000: 255), aunque advierte que algunos grupos artefactuales, tales como las puntas de proyectil, las "grandes lascas con retoque" y las palas y/o azadas líticas, "...son el resultado material de un comportamiento conservativo" (2000: 258). Con respecto a los momentos Tardío y Tardío-Inca, Elías (2007: 62) encuentra que en Antofagasta de La Sierra existe un "...incremento de la expeditividad en la producción de los instrumentos líticos..." en relación con los momentos tempranos a los que alude Escola.

Respecto a las palas y/o azadas líticas, las investigaciones permiten afirmar que responden al uso de una tecnología dirigida a su conservación. Se trata de instrumentos estandarizados, enmangados y con una larga vida útil, lo cual implica un costo medido en inversión de tiempo y energía dedicada a la obtención del producto final y un costo de tiempo, trabajo y efectividad para realizar las actividades (Pérez 2003a y 2010). Efectivamente, las palas y/o azadas líticas del Formativo no tienen formatización sumaria, por el contrario, fueron manufacturadas por retalla y retoque, con regularización de bordes y embotamiento intencional de determinados filos de la pieza. La formatización de este tipo de instrumentos requiere el conocimiento de una técnica especializada para lograr el producto final, la cual consume una importante inversión de trabajo (Pérez 2003a, 2003b, 2006). En este punto es importante destacar que, según el estado actual de las investigaciones, en los conjuntos correspondientes a momentos tardíos no existe una baja inversión de trabajo para producir los artefactos, por el contrario, hay una mayor especialización en la obtención del producto final en relación a momentos tempranos (Formativo); es decir, a la inversión de trabajo para obtener los artefactos por medio de técnica de talla, la cual implica un alto grado de especialización del operador para obtener el producto final, se suma la incorporación de técnica por pulido en la formatización final de ciertos filos, resultando en un costo agregado (plus) en cuanto a tiempo y energía invertida.

El análisis de ambas colecciones, CCHM y Doncellas, asignables a momentos formativos y tardíos, respectivamente, indica que los conjuntos artefactuales presentan una variabilidad interna importante respecto de la técnica de manufactura, la morfología general del cuerpo y tipo de materia prima utilizada. Esta variabilidad determina la necesidad de explicar cuales son los factores involucrados en el cambio observado.

La complejización en la organización de las sociedades del NOA está evidenciada en aspectos de diversa índole. Olivera y Vigliani (2000-2002), plantean que desde ca. 1000 AP, en la microrregión de Antofagasta de la Sierra han habido cambios en el aprovechamiento del espacio productivo del fondo de cuenca entre las ocupaciones formativas y tardías, abandonando las áreas próximas al río y desplazando el área de habitación a los sectores aledaños en el pie de monte de los Cerros del Coypar. Este cambio habría permitido el aprovechamiento de terrenos aptos para el cultivo extensivo e intensivo, liberando las vegas como áreas de pasturas para los rebaños. La producción agrícola se habría intensificado a partir del desarrollo de nuevas tecnologías agrícolas, como por ejemplo, sistemas agrícolas hidráulicos, iniciando una paulatina modificación en la organización social y política de los grupos humanos. Sistemas de canales y cuadros de cultivo de piedra construidos en la ladera inferior de los cerros del Coypar dan evidencia de ello.

El "yacimiento del río Doncellas", por su parte, es un complejo sistema de asentamiento constituido por diversos sitios con arquitectura muy desarrollada, con sectores de diversas actividades claramente delimitados y áreas de actividad ceremonial. Tal es el caso de las evidencias presentes en diversos sectores del poblado, la Estructura Escalonada (monumento ceremonial), o Cueva de Tajuera. Así también, los andenes y acequias reflejan una intensificación agrícola importante. Una sociedad con este grado de complejidad necesita una estructura política, social y económica que permita el control y funcionamiento del sistema.

Es indiscutible la importancia de la economía productiva en este proceso, con estrategias acordes a sus necesidades, sistemas agrícolas hidráulicos y una ergología lítica adecuada para hacer más productivas las actividades. Ahora bien, la variabilidad demostrada en este trabajo indica un cambio en la organización tecnológica. El interrogante, entonces, es determinar si esta variabilidad en las estrategias implementadas en las técnicas de producción artefactual, en las características morfológicas de los instrumentos y en el uso de materia prima, responden a la funcionalidad diferencial de los instrumentos, necesaria para realizar actividades específicas, o si está vincula- 
da a aspectos organizativos de los sitios. En este último caso, la realización o intensificación de actividades relacionadas con las nuevas estrategias de producción de alimentos y las técnicas involucradas en ello, requirieron un cambio o complejización de los conjuntos artefactuales para satisfacer con mayor eficacia las necesidades, las cuales no se podrían concretar con instrumentos que no posean las características de las palas y/o azadas líticas.

De acuerdo a Binford:

"We can expect many such tool-design parallels, that is tools of very different design being used for identical tasks; but this is not to say that they are functionally isomorphic, since they are clearly designed for very different intended roles within the technology" (1979: 269).

A través de análisis tecnológicos y funcionales de palas y/o azadas líticas, es posible aproximarnos al rol que cumplían esos implementos en las estrategias implementadas por sociedades con economías productoras. Un punto importante es establecer la asociación de los instrumentos con las áreas productivas para comprender el cambio en la organización de sociedades agropastoriles tempranas (formativas) a otras más complejas (tardías), con un sistema productivo agrícola pleno.

Nuestras apreciaciones en cuanto a la asignación de palas y/o azadas líticas en el proceso productivo de una comunidad, es decir, el rol económico en el sistema productivo, se basaron en la presencia o ausencia de dichos instrumentos en el contexto arqueológico.

La investigación logró obtener importante información que permite dar cuenta de la variabilidad existente en los conjuntos líticos y abre una puerta para continuar con el estudio tecnológico y funcional de artefactos agrícolas. Al mismo tiempo, es útil como marco de referencia para discutir los datos tecnológicos dentro de un contexto más amplio de análisis, como el cambio en la organización tecnológica y su relación con la complejización de las sociedades que poblaron el NOA.

Queda planteada la necesidad de realizar replicación de instrumentos por medio de técnica de pulido, para obtener nueva información sobre la tecnología. La colección obtenida se incluirá dentro del programa experimental, a fin de contar con una colección de referencia para el análisis de rastros producidos por las actividades llevadas a cabo. Como perspectiva futura se incluye el análisis de muestras provenientes de otros niveles estratigráficos del sitio CCHM, así como también, de muestras recolectadas en diferentes áreas de la fuente de aprovisionamiento Los Negros, a fin de determinar si existe variabilidad interna.

Por último, las escasas investigaciones arqueológicas que abarcan estudios líticos en el área de Doncellas (Puna de Jujuy) avalan la necesidad de realizar trabajos sistemáticos de relevamiento para identificar los recursos líticos existentes, así como análisis de los materiales arqueológicos recuperados.

Agradecimientos A Víctor Costantino por su ayuda en el procesamiento de las imágenes. A Patricia Campán por la traducción del resumen al inglés. A Julio Ávalos por el intercambio de información acerca de tecnología lítica. Al Instituto Nacional de Antropología y Pensamiento Latinoamericano (INAPL) por brindarme el lugar de trabajo y permitir el acceso a la Colección Doncellas. A los evaluadores de este trabajo cuyos comentarios lo enriquecieron.

\section{* Referencias citadas}

ALFARO, L., 1983. Investigación arqueológica en la cuenca del río Doncellas (prov. de Jujuy). Integración de la Puna jujeña a los centros cúlticos andinos. Relaciones de la Sociedad Argentina de Antropología N.S. XIV (2): 25-47.

1988. Excavación de la cuenca del río Doncellas. Reconstrucción de una cultura olvidada en la Puna jujeña. Imprenta del Estado de la Provincia de Jujuy, San Salvador de Jujuy.
ALFARO, L. y J. M. SUETTA, 1976. Excavaciones en la cuenca del río Doncellas. Antiquitas 22-23: 1-32.

ASCHERO, C., 1975 Ms. Ensayo para una clasificación morfológica de artefactos líticos aplicada a estudios tipológicos comparativos. Informe CONICET, Buenos Aires.

1983 Ms. Ensayo para una clasificación morfológica de ar- 
tefactos líticos. Apéndices A y B (revisión 1987). Cátedra de Ergología y Tecnología. Universidad de Buenos Aires, Buenos Aires.

ASCHERO, C., P. ESCOLA, S. HOCSMAN y J. MARTÍNEZ, 2002-2004. Recursos líticos en la escala microrregional Antofagasta de la Sierra, 1983-2001. Arqueología 12: 9-36.

ÁVALOS, J. C., 1998. Modos de uso de implementos agrícolas de la Quebrada de Humahuaca y Puna a través del análisis de huellas de desgaste. En Los desarrollos locales y sus territorios. Arqueología del NOA y surde Bolivia, B. Cremonte (Ed.), pp. 285-303. Universidad Nacional de Jujuy, San Salvador de Jujuy.

BINFORD, L., 1973. Interassemblage variability: The Mousterian and the "functional" argument. En The explanation of culture change: Models in prehistory, C. Renfrew (Ed.), pp. 227-254. Dickmorth Press, Londres.

1979. Organization and formation processes: Looking at curated technologies. Journal of Anthropological Research 35 (3): 255-273.

BINFORD, L. y S. BINFORD, 1966. A preliminary analysis of functional variability in the Mousterian of Levallois facies. American Anthropologist 68 (2): 238-295.

BOGGS, S., 1992. Petrology of sedimentary rocks. Macmillan Publishing Company, Nueva York.

BOMAN, E., 1992 [1908]. Antigüedades de la región andina de la República Argentina y del desierto de Atacama. Universidad Nacional de Jujuy, San Salvador de Jujuy.

BORDES, F., 1961. Typologie du Paléolitique ancien et moyen. Publications de l'Institut de Préhistoire de l'Université de Bordeaux. Memoire 1. Imprimeries Delmas, Bordeaux.

BORDES, F. y D. DE SONNEVILLE-BORDES, 1970. The significance of variability in Paleolithic assemblages. World Archaeology 2: 61-73.

CARRASCO, C., 2003. Los artefactos de molienda durante los períodos Intermedio Tardío y Tardío en San Pedro de Atacama y Loa Superior. Estudios Atacameños 25: 35-53.

2004. Uso de tecnologías líticas entre el Arcaico Tardío y el período Formativo Tardío: El modelo de la localidad de Caspana. Chungara, Revista de Antropología Chilena 36 (1): 29-35.

CASANOVA, E., 1933. Tres ruinas indígenas en la quebrada de La Cueva. Anales del Museo Nacional de Historia Natural "Bernardino Rivadavia" XXXVII: 272-276.
DEBENEDETTI, S. y E. CASANOVA, 1935. Titiconte. Publicaciones del Museo Antropológico y Etnográfico de la Facultad de Filosofía y Letras, serie A III: 7-35.

ELÍAS, A., 2007. Tecnología lítica en las sociedades tardías de Antofagasta de la Sierra (Puna Meridional argentina). Estudios Atacameños, Arqueología y Antropología Surandinas 33: 59-85.

ELÍAS, A. y P. TCHILINGUIRIAN, 2006. Aplicación del análisis petrográfico en recursos líticos (Antofagasta de la Sierra, prov. de Catamarca, Puna Meridional argentina). Actas del $1^{\text {er }}$ Congreso Argentino de Arqueometría "Metodologías Científicas Aplicadas al Estudio de los Bienes Culturales" (2005), A. Pifferetti y R. E. Bolmaro (Eds.), pp. 208-217. Rosario.

ELÍAS, A., P. ESCOLA y P. TCHILINGUIRIAN, 2007. ¿Cómo dos gotas de agua?: Análisis petrográfico de recursos líticos de la microrregión Antofagasta de la Sierra (prov. de Catamarca, Puna Meridional argentina). Resúmenes del $2^{\circ}$ Congreso Argentino y $1^{\circ}$ Latinoamericano de Arqueometría, T. Palacios (Ed.), pp. 84-85. Comisión Nacional de Energía Atómica, Centro Atómico Constituyentes, Buenos Aires.

ESCOLA, P., 1990-1992. Explotación y manejo de recursos líticos en un sistema adaptativo formativo de la Puna argentina. Arqueología Contemporánea 3: 5-19.

1991. Proceso de producción lítica: Una cadena operativa. Shin-

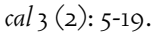

2000. Tecnología lítica y sociedades agropastoriles tempranas. Tesis para optar al grado de Doctor en Filosofía y Letras. Facultad de Filosofía y Letras, Universidad de Buenos Aires, Buenos Aires.

2004. La expeditividad y el registro arqueológico. Chungara, Revista de Antropología Chilena 36 (1): 49-60.

GASTALDI, M. R., 2001. Tecnología y sociedad: Biografía e historia social de las palas del oasis de Tebenquiche Chico. Tesis de Licenciatura en Arqueología. Escuela de Arqueología de la Universidad Nacional de Catamarca, Catamarca.

HABER, A. y M. R. GASTALDI, 2006. Vida con palas. Antípoda. Revista de Antropología y Arqueología 2: 275-302.

HOCSMAN, S., 2006. Tecnología lítica en la transición de cazadores recolectores a sociedades agropastoriles en la porción meridional de los Andes Centro Sur. Estudios Atacameños, Arqueología y Antropología Surandinas 32: 59-73.

LATCHAM, R., 1938. Arqueología de la región atacameña. Prensas de la Universidad de Chile, Santiago. 
MÁRQUEZ MIRANDA, F., 1939. El "pucara” del pie de la cuesta de Colanzulí. Notas preliminares Museo de La Plata II: 259-269.

MÉNDEZ, C., 2007. Tecnología lítica en el Camino Inca del Alto Loa, norte de Chile. Estudios Atacameños, Arqueología y Antropología Surandinas 33: 39-57.

NAMI, H., 1992. El subsistema tecnológico de la confección de instrumentos líticos y la explotación de los recursos del ambiente: Una nueva vía de aproximación. Shincal 2:33-53.

NELSON, M., 1991. The study of technological organization. Archaeological Method and Theory vol. 3, M. Schiffer (Ed.), pp. 57100. University of Arizona Press, Tucson.

OLIVERA, D., 1987 Ms. Nueva aproximación al Formativo de la Puna Meridional argentina: Tecnología, estrategias adaptativas y proceso cultural. Informe CONICET, Buenos Aires.

1991a. El Formativo en Antofagasta de la Sierra (Puna Meridional argentina): Análisis de sus posibles relaciones con contextos arqueológicos agroalfareros tempranos del NOA y norte de Chile. XI Congreso Nacional de Arqueología Chilena, vol. 2, pp. 71-78. Museo Nacional de Historia Natural, Sociedad Chilena de Arqueología, Santiago.

1991b. Tecnología y estrategias de adaptación en el Formativo (Agroalfarero Temprano) de la Puna Meridional argentina. Un caso de estudio: Antofagasta de la Sierra (prov. de Catamarca, Argentina). Tesis doctoral en Ciencias Naturales. Facultad de Ciencias Naturales, Universidad Nacional de La Plata, Buenos Aires.

OLIVERA, D. y A. NASTI, 1993. Site formation processes in the Argentine Northwest Puna: Taphonomic researches on archaeofaunistic record preservation. Arqueología Contemporánea 4:-85-98.

OLIVERA, D. y S. VIGLIANI, 2000-2002. Proceso cultural, uso del espacio y producción agrícola en la Puna Meridional argentina. Cuadernos del Instituto Nacional de Antropología y Pensamiento Latinoamericano 19: 459-481.

PÉREZ DE MICOU, C., 1998. Las colecciones arqueológicas y la investigación. Revista Do Museu de Arqueología e Etnología 8: 223-233.

PÉREZ, S., 2003a. Experimentación y análisis de microdesgaste de palas y/o azadas líticas de Antofagasta de la Sierra (Catamarca). Tesis de Licenciatura en Ciencias Antropológicas, orientación Arqueología. Facultad de Filosofía y Letras, Universidad de Buenos Aires, Buenos Aires.

2003b. Aproximación experimental aplicada a la determina- ción funcional de palas y/o azadas líticas. Hombre y Desierto. Una Perspectiva Cultural 11: 85-113.

2004a. Experimentación de uso con palas y/o azadas líticas. Intersecciones en Antropología 5: 105-117.

2004b. Experimentación de enmangue de palas y/o azadas líticas. Resúmenes del XV Congreso Nacional de Arqueología Argentina. Universidad Nacional de Río Cuarto, Córdoba.

2005. Análisis de microdesgaste por uso de palas y/o azadas líticas de Antofagasta de la Sierra (prov. de Catamarca.) Aportes para su interpretación funcional. Hombre y Desierto. Una Perspectiva Cultural 12: 23-46.

2005 Ms. Análisis técnico-morfológico de palas y/o azadas líticas de la Colección Doncellas.

2006. Arqueometría de palas y/o azadas líticas aplicada a estudios experimentales. El caso de Antofagasta de la Sierra (Catamarca). Actas del Primer Congreso Argentino de Arqueometría "Metodologías Científicas Aplicadas al Estudio de los Bienes Culturales" (2005), A. Pifferetti y R. E. Bolmaro (Eds.), pp. 230-240. Rosario.

2008. La organización de la tecnología lítica en el Noroeste Argentino. Aproximación a través de experimentación, análisis tecno-morfológico y de microdesgaste por uso de palas y/o azadas líticas. Comechingonia. Revista Electrónica de Arqueología 2 (3): 186-222.

2010. Estrategias tecnológicas conservadas en contextos agropastoriles tempranos de la Puna Meridional argentina. Chungara, Revista de Antropología Chilena 42 (2): 405-418.

PÉREZ, S., P. TCHILINGIRIAN y P. ESCOLA, 2006. Caracterización de la materia prima utilizada en palas y/o azadas líticas de la Puna argentina. Actas del Primer Congreso Argentino de Arqueometría "Metodologías Científicas Aplicadas al Estudio de los Bienes Culturales"(2005), A. Pifferetti y R. E. Bolmaro (Eds.), pp. 218-229. Rosario.

PETTIJOHN, F. J., 1980. Rocas sedimentarias. Eudeba, Buenos Aires.

PODESTÁ, M., 1986-87. Arte rupestre en asentamientos de cazadores recolectores y agroalfareros en la Puna Sur argentina: Antofagasta de la Sierra, Catamarca. Relaciones de la Sociedad Argentina de Antropología N.S. XVII: 1: 241-263.

1988. Soportes y tecnología de grabados rupestres. Resúmenes del IX Congreso Nacional de Arqueología Argentina, pp. 42. Universidad de Buenos Aires, Buenos Aires.

1991. Cazadores y pastores de la Puna: Apuntes sobre sus manifestaciones de arte rupestre. Shincal 3: 12-16. 
PODESTÁ, M., L. MANZI, A. HORSEY y M. P. FALCHI, 1991. Función e interacción a través del análisis temático en el arte rupestre. En El arte rupestre en la arqueología contemporánea, M. Podestá, M. I. Hernández Llosas y S. Renard (Eds.), pp. 40-52. Salón Integral Editora, Buenos Aires.

VON ROSEN, E., 1924. Popular account of archaeological research during the Swedish Chaco - Cordillera-Expedition, 1901-1902. Editorial Bonier, Estocolmo.
YACOBACCIO, H., 1983. Estudio funcional de azadas líticas del NOA. Arqueología Contemporánea 1 (1):3-19.

YERKES, R. W. y P. N. KARDULIAS, 1993. Recent developments in the analysis of lithic artifacts. Journal of Archaeological Research 1 (2): 89-119. 